\title{
GÊNEROS: TEORIAS, MÉTODOS, DEBATES
}

GÉNERO: TEORÍAS, MÉTODOS, DEBATES

GENRE: THEORIES, METHODS, DEBATES

Sandra POTTMEIER ${ }^{1}$

Lais Oliva DONIDA ${ }^{2}$

Aline Olin Goulart DARDE ${ }^{3}$

Abordar o tema "gênero" na atualidade vem sendo um mister de aproximações e distanciamento nas discussões e conceituações acerca deste. Contudo, se faz necessário (re)conhecer os avanços na área que procedem de diversas correntes teóricas. O livro em questão, “Gêneros: teorias, métodos, debates" foi elaborado a partir das discussões do Grupo de Trabalho - GT da Associação Nacional de Pós-Graduação e Pesquisas em Letras e Linguística (ANPOLL). Os membros do subGT “Teorias de gênero (genre) em práticas sociais” foram os responsáveis pela organização do livro, sendo eles: Luiz José Meurer (in memorian) e Adair Bonini, ambos doutores em Linguística e docentes na Universidade Federal de Santa Catarina, seguidos de Desirée Motta-Roth, doutora em Letras e docente na Universidade Federal de Santa Maria. Disposto em 295 páginas e publicado pela primeira vez em 2005 pela editora Parábola Editorial, apresenta ao leitor doze capítulos a partir de três importantes abordagens: Parte 1: Abordagens sociossemiótica; Parte 2: Abordagens sociorretóricas, e; Parte 3: Abordagens sociodiscursivas.

Os debates tecidos ao longo da obra têm como principal objetivo "estabelecer um mapeamento dos principais conceitos, termos e explicações disponíveis" (MEURER; BONINI; MOTTA-ROTH, 2005, p. 7). De certa forma, propõe sistematizar

${ }^{1}$ Universidade Federal de Santa Catarina (UFSC), Florianópolis - SC - Brasil. Doutoranda do Programa de Pós-Graduação em Linguística. ORCID: https://orcid.org/0000-0001-7328-8656. E-mail: pottmeyer@gmail.com

${ }^{2}$ Universidade Federal de Santa Catarina (UFSC), Florianópolis - SC - Brasil. Doutoranda do Programa de Pós-Graduação em Linguística. ORCID: http://orcid.org/0000-0003-3508-7030. E-mail: lais.donida@gmail.com

${ }^{3}$ Universidade Federal de Santa Catarina (UFSC), Florianópolis - SC - Brasil. Doutoranda do Programa de Pós-Graduação em Linguística. ORCID: https://orcid.org/0000-0001-8808-8606. E-mail: alineolin@yahoo.com.br 
os debates de base, introdutórios ao tema gênero, em suas problemáticas atuais e conceituais, oferecendo também um olhar crítico aos métodos e as teorias, bem como tem a pretensão de estabelecer um direcionamento no que diz respeito ao desenvolvimento de pesquisadores e de novos estudos na área. Revela, assim que o aporte teórico apresentado também se preocupa na manutenção do diálogo com a criticidade dos próprios métodos empregados e com a formação do cientistapesquisador. Corroborando com a ideia de que há lacunas nos estudos em Linguística Aplicada no país, Rodrigues (2007, p. 249) pontua que esse livro prontamente se encaixa a resolução deste problema ao buscar "atenuar a carência da área em termos de publicações que viabilizem o diálogo entre as diferentes abordagens sobre o assunto".

Atenta-se aos direcionamentos realizados pelos organizadores no prefácio ao situarem o leitor quanto aos termos utilizados para os estudos e trabalhos com gêneros. Portanto, os termos "gênero discursivos", "gêneros do discurso", "gêneros textuais", "gêneros de texto", bem como outros empregos utilizados ao longo dos capítulos, refletem a variedade de compreensões acerca do mesmo objeto de pesquisa: o uso da linguagem em contextos e práticas sociais. Estes, ao mesmo tempo em que se distanciam teórica e conceitualmente, se aproximam e se sobrepõem, uma vez que não há dissonância radical entre os estudiosos e tampouco definição exata e imutável. Deste modo, há a divisão das discussões entretecidas em três grandes grupos acima situados, os quais convergem a partir de um olhar social da/para/sobre/com a linguagem e divergem no tocante à teoria e o seu tratamento quanto à análise do gênero discursivo/textual.

A "Parte 1: Abordagens sociossemióticas" é composta por cinco capítulos que tem como foco, a organização da linguagem e sua relação com o uso e o modo como a linguagem e o contexto social em que é produzida se inter-relacionam, de modo que um realize o outro. De modo geral, a abordagem sociossemiótica surge na década de 1970 a partir das discussões sobre o conceito de contexto. Há, nesse período, uma virada da pragmática da língua, compreendendo-se assim, os usos da língua segundo o contexto de atuação (língua como estrutura e funcional). Os estruturalistas, Halliday e Hasan, principais representantes da Escola de Sidney, migraram para o funcionalismo da língua, conhecida como sistêmico-funcional. Portanto, a linguagem é concebida na sociossemiótica a partir de um sistema de escolhas e o seu uso se dá através de um meio social determinado, o qual os sujeitos (usuários) possam interagir nas diversas esferas 
da atividade humana. Logo, o conceito de gênero, antes compreendido por esta Escola a partir da Linguística Textual, passa a estudar o texto, gênero e discurso sem separá-los.

O primeiro capítulo, intitulado "O conceito de 'estrutura potencial do gênero' de Ruqayia Hasan”, de autoria de Désirée Motta-Roth e Viviane Heberle, perpassa princípios teóricos de Halliday e Bernstein, propondo investigar o componente semântico e o modo como sua relação linguística varia. Nessa perspectiva, o social não deve ser ignorado, pois se crê que as relações sociais influenciam os padrões de seleção "do que é dito, quando é dito e como é dito" (MOTTA-ROTH; HEBERLE, 2005, p. 12). Hasan integra texto e contexto argumentando que é possível perceber quais elementos da estrutura textual são obrigatórios e quais são opcionais a partir da análise da configuração do contexto. A partir destas conceituações, Hasan define que Estrutura Potencial do Gênero (EPG), na relação funcional entre linguagem e contexto da situação, estaria relacionado a como cada gênero corresponde aos padrões recorrentes e contextuais. O modo, a relação e o campo são responsáveis pela configuração contextual e permitem fazer previsões sobre qualquer texto em um determinado contexto. Sendo assim, se pode considerar qualquer texto como um exemplo potencial de um gênero específico. O objetivo da EPG é dar conta do leque de opções de estruturas esquemáticas específicas potencialmente disponíveis aos textos de um mesmo gênero, de tal forma que as propriedades crucias de um gênero possam ser abstraídas e qualquer exemplar desse gênero possa ser representado. $O$ capítulo também traz discussões acerca do gênero resenha acadêmica e a aplicação teórico-metodológica da EPG. A partir disso, se permite observar uma abordagem da linguagem como aquela que dialoga com o texto, contexto situacional e o contexto de cultura.

O segundo capítulo, intitulado "A perspectiva teleológica de Martin para a análise dos gêneros textuais”, de autoria de Orlando Vian Jr e Rodrigo Lima-Lopes, discorre sobre uma proposta que considera o gênero como um sistema estruturado em partes, com meios específicos para fins específicos, de caráter teleológico, mutável, uma vez que se trata de um sistema aberto sujeito a cada atividade humana. Martin se utiliza de trabalhos de Halliday, Mathiesen e Bakhtin para formular sua perspectiva teórica e propõe a ampliação dos conceitos de gênero e registro, cujo foco está nos aspectos do contexto de cultura e de situação, observando seu contexto imediato de realização. Ele também defende que o registro funcionaria como uma forma de instanciação do gênero, em que a cultura é tomada como um sistema de gêneros, de processos sociais. Ou seja, o gênero é instanciado mediante escolhas das variáveis de registro, em que as pré- 
seleciona e as associa a partes específicas da estrutura textual. Quanto aos conceitoschave, compreende que o gênero é definido a partir do contexto de cultura e de registro (escrito ou falado/imagético, que são as escolhas que dependem do contexto de situação). Martin discorda de Hasan quanto ao seu ponto de partida estar centrado no registro, afirmando que é preciso estudar as interações autênticas e completas, na qual se possa observar como as pessoas usam a língua para atingir seus objetivos culturalmente motivados. Como representante da Escola de Sidney, Martin corrobora com a concepção de ensinar pelo e do gênero, pois a cultura acaba exigindo isso dos interlocutores, os quais, durante a comunicação, estão inseridos em um contexto de situação (registro) e contexto de cultura. A apropriação do gênero ocorre assim, como forma de interação. Os autores finalizam o capítulo apresentando ao leitor uma análise de "cartas" sob essa perspectiva analítica.

O terceiro capítulo, intitulado "A noção de gênero textual na linguística crítica de Roger Fowler", de autoria de Sumiko Ikeda, traz uma abordagem em que se ancora na Análise Crítica do Discurso (ACD), utilizando preceitos da "linguística crítica" de Fowler, Fairclough, Pêcheux e outros. Nessa perspectiva, o discurso é constituído socialmente e perpassado pelas ideologias e a linguagem é aquela que passa a confirmar e a concretizar os discursos das organizações/instituições que as permeiam e as moldam, de acordo com a posição que os sujeitos (usuários da língua) ocupam em determinado tempo e espaço. Portanto, a Linguística Crítica de Fowler, caracteriza o texto como o incorporador das ideologias que circulam socialmente, buscando compreender criticamente os axiomas sociais e ideológicos que os usuários fazem em seus contextos de uso, ou seja, as suas escolhas linguísticas. Fowler atém-se na análise e interpretação da linguagem no gênero jornal, afirmando que "qualquer aspecto da estrutura linguística carrega significação ideológica" (IKEDA, 2005, p. 48). Assim, o modo como é dito o que é dito, carrega sentidos que podem ser interpretados por um ou outro viés e carece de um olhar crítico para desvelar os sentidos implícitos do texto. A autora Ikeda retoma essas discussões trazendo uma análise baseada nos preceitos da ACD do editorial " $\mathrm{O}$ quinto centenário" (Folha de São Paulo, 2000) como discussão e aplicação da perspectiva aqui apresentada (IKEDA, 2005).

No quarto capítulo, "A perspectiva discursivo-semiótica de Gunther Kress: o gênero como um recurso representacional", redigido por Anna Balocco, há a apresentação da proposta de Kress, que concebe os gêneros como tipos de texto "que codificam os traços característicos e as estruturas dos eventos sociais, bem como os 
propósitos dos participantes" (BALOCCO, 2005, p. 65). Assim, a noção de gênero é compreendida como um recurso representacional. Ele enfatiza que determinados eventos sociais que ocorrem em determinadas instituições sociais (uma reunião, por exemplo) apresentam diferenças quanto à forma, mas convergem quanto às práticas. Também assume a relevância da análise de gêneros associada aos elementos nãoverbais que a constituem, pois estes também representam aspectos ideológicos marcados no texto. Esse autor se utiliza de enfoque teórico a partir de práticas sociais e perpassadas por aspectos histórico-culturais, além de compreender a língua como um sistema de signos utilizados para construir sentidos, o qual denomina de perspectiva discursivo-semiótica. Outra contribuição se faz em relação à construção de sentidos e sua análise em dois campos: um imediato (eventos sociais) e outro mais geral (o da cultura). Essa perspectiva analisa os gêneros como tipos de texto (orais/escritos), em que elementos não-verbais e verbais devem ser estudados conjuntamente para/na/sobre a construção dos sentidos em vários contextos de uso da linguagem. Encerrando-se o capítulo, segue uma discussão acerca da aplicação da teoria em que se discute o gênero em coming out stories.

Por fim, o quinto capítulo "Gêneros textuais na análise crítica de Fairclough”, redigido por José Luiz Meurer, encerra a sessão de textos abordados sob a perspectiva da sociossemiótica, discorrendo sobre a concepção de análise de textos como inseridos em práticas sociais e por elas constituídas, permeadas e direcionadas por ideologias, relações de discursos de poder e produzidas e consumidas dentro daquela esfera de interação. Ao mesmo tempo em que critica várias áreas como a pragmática, a sociolinguística, a linguística tradicional, entre outras, Fairclough também incorpora aspectos que considera relevantes dessas teorias. Este autor também considera a linguagem como sendo parte integrante nas relações sociais e como processo de transformação social. Segundo Meurer (2005, p. 82), o gênero "ocorre em determinado contexto e envolve diferentes agentes que o produzem e o consomem”. Logo, o uso da linguagem, permite a sua (re)produção a partir da manutenção ou mudança das relações sociais de poder. Ou seja, os usurários (atores sociais) escolhem os gêneros que desejam e a forma como estes serão usados em seus mais variados contextos. A Análise Crítica do Discurso se concretiza, portanto, a partir de três eixos essenciais: texto, práticas discursivas e práticas sociais. Meurer distingue, neste capítulo, com o intuito didático, duas vertentes para a proposta de Fairclough: uma de cunho teórico e outra de cunho 
metodológico, apresentando pressupostos teóricos para a análise de texto como evento comunicativo, prática discursiva e social.

Dando continuidade, a "Parte 2: Abordagens sociorretóricas" apresenta dois capítulos que dissertam sobre a influência da retórica de Swales, Miller e Bazerman quanto à análise de gêneros. Utilizada incialmente apenas no campo da estratégia e persuasão, essa abordagem posteriormente expandiu seus escopos para o ensino de composição argumentativa e incorporou aspectos dos estudos do Círculo de Bakhtin que enriqueceram, principalmente, a discussão sobre propósito e contexto e ação social. De modo geral, a Escola norte-americana surge no final do século XIX como uma resposta ao ensino da escrita tal qual estava posto, em que se baseava em uma retórica clássica, ou seja, voltada ao ensino das belas-letras e das obras literárias e, portanto, mais centrada na estilística, na correção sintática/gramatical, não considerando as características retóricas ou pragmáticas. Para tanto, os posicionamentos dos estudiosos dessa Escola, provocaram discussões levando os docentes a (re)pensar sobre a sua prática educacional, bem como, a elaborar outros procedimentos/metodologias de ensino e aprendizagem que considerassem o contexto em que cada estudante estava inserido. Os gêneros passam a ser compreendidos nesse contexto como tipos textuais apresentando regularidades linguístico-textuais e são definidos como ações responsivas a/em diversificados contextos sociais e em uma dada cultura (o foco não está na estrutura do discurso/enunciado, mas na prática em que se efetiva a partir do gênero escolhido/em uso).

O sexto capítulo, intitulado "A proposta socio-retórica de John M. Swales para o estudo de gêneros textuais", redigido por Barbara Hemais e Bernadette BiasiRodrigues, discorre sobre o estudo e a análise de gêneros textuais sob aporte teóricometodológico proposto por Swales, que concebe que o texto não é e não pode ser completamente entendido e interpretado em seu contexto se utilizando apenas de aspectos linguísticos, pois a produção escrita do gênero em determinada esfera social necessita de conhecimentos que excedem esse aspecto e dependem do propósito comunicativo. Toda a proposta teórica de Swales é influenciada pela ideia de que há classes de eventos comunicativos, em que estas se constituem pelo discurso, pelos participantes, a função do discurso e do ambiente. E, nessas classes de eventos comunicativos (ou conjuntos de eventos comunicativos), há propósitos comunicativos que direcionam para objetivos fins. A prototipicidade também é relevante nesta proposta, uma vez que o gênero só se constituirá como gênero se possuir características 
que o determinam como tal. Swales ainda propõe que os gêneros possuem uma "razão subjacente", reconhecida pelos membros da comunidade em convenção, pois serve para determinado propósito comunicativo e possuem uma terminologia própria elaborada pela comunidade discursiva. As autoras do capítulo enfatizam que gênero para Swales é o resultado de várias interlocuções entre/de diversos campos de estudo (Antropologia, Etnografia, entre outros). O capítulo finaliza com uma análise baseada no modelo Create A Research Space (CARS) de introduções de artigos de pesquisa.

O sétimo capítulo, "Gênero como ação social em Miller e Bazerman: o conceito, uma sugestão metodológica e um exemplo de aplicação”, apresentado por Gisele de Carvalho, discorre acerca de noções como recorrência e ação retórica a partir dos estudos de Miller e Bazerman. Os gêneros são aqui compreendidos como ações sociais tipificadas (tipos ou formas de agir socialmente em diversos contextos), definidas pelos seguintes propósitos: funções, intenções, interesses. Bazerman também situa seu trabalho na perspectiva de gênero como ação social, em que os textos apresentam regularidades na forma e no conteúdo. Nesse capítulo, a autora traz uma aplicação teórica e metodológica com o gênero resenha acadêmica como encerramento da sessão.

A última sessão, "Parte 3: Abordagens sociodiscursivas", é constituída por cinco capítulos que partem de uma perspectiva mais direcionada à Escola de Genebra, tendo como principais representantes Bronckart, Schneuwly e Dolz. Ela surge na década de 1980 e defende uma "didática da diversificação". Logo, essa Escola rompe com o sistema tradicional de ensino de línguas na escola, o da gramática, da decodificação, focado na língua, o qual não considerava os usos de linguagem como social e histórico, utilizando-se do Interacionismo Sócio-Discursivo (ISD) que se pauta nos tipos de discurso, ou seja, nas tipologias e nos elementos que o constituem.

O capítulo oito, "Os gêneros do discurso na perspectiva dialógica da linguagem: a abordagem de Bakhtin”, redigido por Rosângela Hammes Rodrigues, concebe os gêneros do discurso a partir da perspectiva bakhtiniana como aqueles que são historicamente constituídos nas vivências, nas relações entre os sujeitos, a partir das práticas de uso da língua(gem) em diversas esferas da atividade humana. Utiliza a partir dos estudos do Círculo de Bakhtin o conceito de gêneros primários (os quais são expressos na comunicação espontânea: na família, a partir de cartas, bilhetes, por exemplo) e; gêneros secundários (mais complexos e evoluídos e constituídos pelos primários, como o romance, a resenha). Os gêneros, assim, têm propósitos discursivos específicos em/para cada esfera social a partir do conteúdo temático, composição e 
estilo que apresentam a partir das relações dialógicas/de interação verbal. Nessa proposta perpassam concepções de caráter histórico, social e ideológico da língua(gem), do enunciado e da atividade humana, o que contribuiu para as bases teóricas e críticas de muitas outras abordagens que buscavam compreender a analisar os gêneros e suas manifestações na sociedade e na interação. De caráter bastante teórico, ao final, a autora ainda traz uma análise de gênero baseada em artigo da esfera jornalística como forma de exemplificar a aplicação teórico-metodológica desta perspectiva.

O capítulo nove, "Gêneros do discurso e gêneros textuais: questões teóricas e aplicadas", de autoria de Roxane Rojo, busca resgatar criticamente estudos sobre o letramento, datados a partir do ano de 1995 no Brasil, circunscritos às esferas de produção acadêmica de áreas como a Linguística Aplicada e voltados ao ensino de línguas. Assim, divide os estudos em duas vertentes: teoria de gêneros do discurso/discursivos sob a concepção presente na obra bakhtiniana e teorias de gêneros de texto/textuais a partir da proposta do grupo genebrino de didática de línguas (Bronckart, Schneuwly, Dolz). Dessa forma, pretende conceituar essas duas vertentes sob um viés teórico e metodológico, trazendo seus principais conceitos e estudiosos. Concebe uma análise dialógica de uma conversa familiar e finaliza o capítulo enfatizando a questão do posicionamento da Linguística Aplicada dentro desse campo de pesquisa.

\section{O capítulo dez intitula-se "A noção de sequência textual na análise pragmático-} textual de Jean-Michel Adam", de autoria de Adair Bonini, que discorre acerca de questões de noção de sequência textual de Jean-Michel Adam, esta que se relaciona à Linguística Textual e à Análise do Discurso de linha Francesa. Adam categoriza os gêneros a partir dos traços que eles apresentam e que comungam com as sequências, entendidas por ele como protótipos e "pensadas a partir dos conceitos de base e tipo de texto e de superestrutura textual" (BONINI, 2005, p. 210). Bonini enfatiza que os trabalhos de Adam buscaram construir uma reflexão teórica integrando orientações formais e enunciativas. As sequências seriam então agrupadas em: narrativa, descrição, explicação, argumentação e diálogo e pensadas a partir de conceitos de base e tipo de texto, superestrutura textual, planificação e estruturação. A partir disso, Bonini traz a aplicação desses pressupostos na análise do gênero de exemplares de crítica de cinema e discute a noção de sequência (ou tipo de texto) e o ensino de produção textos (leitura e escuta de textos). 
O capítulo onze, de autoria de Anna Rachel Machado, intitula-se "A perspectiva interacionista sociodiscursiva de Bronckart" e traz uma discussão baseada em preceitos de ordem psicossociológicas dos gêneros, em que o interacionismo sociodiscursivo (ISD) perpassa as ideias de Bronckart. Mas, assim como defendido por Machado, essas epistemes também partem de Dolz e Schnewly, tendo como referência Vigotsky. Machado, caracteriza texto como materialidade, gênero como atividades sociais e discurso como as atitudes que provocamos uns contra os outros, efeitos de sentido por intermédio de gêneros e textos. Bronckart juntamente com os pesquisadores genebrinos, Schneuwly e Dolz, categorizam os gêneros como instrumento para agir discursivamente em um contexto sócio-histórico. Os gêneros, nesta visão, são mediadores das ações discursivas (capacidades individuais) que acontecem entre sujeitos e se relacionam com as atividades linguageiras das/nas diversas esferas humanas. Além disso, Machado faz uma crítica à ISD ao pontuar que esta não analisa os gêneros de texto, partindo apenas das ações verbais e não verbais conduzidas por objetivos epistemológicos específicos. Esse capítulo é em parte teórico, conceituando gênero de texto, tipo de discurso, tipo de sequência, atividade, atividades linguageiras, ação e apresentando um modelo de análise de textos e sua aplicação prática partindo do corpus de resenhas.

O capítulo doze, último capítulo da sessão e, encerrando as discussões teóricometodológicas do livro, é intitulado "Gênero do discurso como componente do arquivo em Domique Maingueneau”, de autoria de Maria Marta Furlanetto. Nesse capítulo se discute a contribuição de Maingueneau e da Análise do Discurso de tradição francesa para os estudos dos gêneros. Maingueneau pontua que, apesar de inicialmente se proporem a definir tipologias, a Análise do Discurso Francesa passa a teorizar os estudos de gêneros do discurso como um meio de atingir a "identidade enunciativa" que o constituiu historicamente, denominando esse aspecto de "arquivo". Além disso, define discurso, texto, gênero e arquivo, como objetos de investigação nessa perspectiva teórico-metodológica. Logo, os gêneros são compreendidos aqui "em sua constituição histórica, circulando na sociedade imediata e mediata dos sujeitos", conforme a posição que ocupam em determinado tempo e espaço a partir das várias instituições a qual se filiam/inscrevem-se (FURLANETTO, 2005, p. 261). Ainda, a autora do capítulo descreve as posições teóricas acerca de interdiscurso, interdizer, formação discursiva, universo discursivo, campo discursivo e espaço discursivo, entre outros conceitos. Furlanetto encerra este capítulo e a última sessão do livro com a análise de um texto, pautado na Análise do Discurso Francesa, denominado "Química da Mulher". 
A partir do exposto, observa-se que a obra resenhada é cunhada por diferentes olhares, teorias e metodologias acerca da noção de gênero textual/discursivo, a qual abarca e também descortina, em uma linguagem clara, questões relevantes que ora unificam e ora distanciam-se entre/das abordagens aqui apresentadas: socio-semióticas, socio-retóricas e socio-discursivas. Portanto, esse livro se destaca pela relevância do tema, uma vez que há ainda poucas produções na área quanto à discussão acerca dos gêneros, a saber, desde sua publicação. Outrossim, a retomada do conceito de gênero constituída a partir de uma heterogeneidade de olhares, sejam eles epistemológicos e/ou metodológicos, tomam a linguagem como uma ação social. Trata-se, portanto, de uma leitura indispensável a estudantes, professores e pesquisadores da área das Ciências da Linguagem e da Educação.

O leitor tem, assim, acesso a um panorama amplo sobre conceito de gênero, seja ele entendido por Bakhtin (2011[1979]) como um gênero do discurso, seja visto como tipos de discurso, como afirma Bronckart (1999), ou atitudes discursivas, como enunciam Baltar e Costa (2010), ou ainda atividades de tipificação (atos de fala), nomeados por Bazerman, Dionísio e Hoffnagel (2005). Portanto, considera-se de grande importância essa heterogeneidade de possibilidades no que concerne aos estudos inseridos na área da linguagem, bem como os múltiplos caminhos que podem ser percorridos daqui por diante. Assim, aos adeptos de propostas baseadas em gêneros, é necessário que a criticidade proposta pela teoria também perpasse a prática, seja ela em pesquisas, na prática pedagógica ou nas mais diversas esferas de atividade humana.

\section{REFERÊNCIAS}

BAKHTIN, M. M. Estética da criação verbal. Tradução do russo Paulo Bezerra. 6. ed. São Paulo: Martins Fontes, 2011[1979].

BALTAR, M. A. R.; COSTA, D. R. da. Gênero textual exposição oral na educação de jovens e adultos. Rev. bras. linguist. apl., Belo Horizonte, v. 10, n. 2, p. 387 402, 2010. Disponível em:

http://www.scielo.br/scielo.php?script=sci_arttext\&pid=S1984$63982010000200006 \& \operatorname{lng}=e n \& n r m=$ iso. Acesso em: 16 set. 2019.

BAZERMAN, C.; DIONÍSIO, A. P.; HOFFNAGEL, J. C. Gêneros textuais, tipificação e interação. São Paulo: Cortez, 2005.

BRONCKART, J.-P. Atividade de linguagem, textos e discursos: por um interacionismo sócio-discursivo. São Paulo: EDUC, 1999. 
MEURER, J. L.; BONINI, A.; MOTTA-ROTH, D. Gêneros: teorias, métodos, debates. São Paulo: Parábola, 2005. 295 p.

RODRIGUES, F. S. MEURER, J. L.; BONINI, A.; MOTTA-ROTH, D. (Org.). Gêneros: teorias, métodos, debates. São Paulo: Parábola Editorial, 2005. 295p. Rev. Brasileira de Lingüística Aplicada, v. 7, n. 1, 2007. p. 249-254. Disponível em: http://www.scielo.br/pdf/rbla/v7n1/12.pdf. Acesso em: 15 set. 2019.

\section{Cómo citar este artículo}

POTTMEIER, S.; DONIDA, L. O.; DARDE, A. O. G. Gêneros: teorias, métodos, debates. Rev. EntreLínguas, Araraquara, v. 5, n. 2, p. 446-456, jul./dez. 2019. E-ISSN: 2447-3529. DOI: 10.29051/el.v5i2.12991

Submetido em: 18/06/2019

Revisões requeridas: 03/07/2019

Aprovado em: 15/07/2019

Publicado em: 01/10/2019 